\title{
Social networks and alcohol consumption among first generation Chinese and Korean immigrants in the Los Angeles metropolitan area
}

\author{
C. Richard Hofstetter ${ }^{1}$, John D. Clapp ${ }^{2}$, Jon-Patrick Allem ${ }^{3}$, Suzanne C. Hughes ${ }^{4}$, Yawen Li $^{5}$, Veronica Irvin ${ }^{6}$, Alan \\ J. Daly ${ }^{7}$, Sunny Kang ${ }^{4}$, and Melbourne F. Hovell ${ }^{1}$ \\ ${ }^{1}$ Center for Behavioral Epidemiology and Community Health, Graduate School of Public Health, and Department of Political Science, San Diego \\ State University, San Diego, CA, United States \\ ${ }^{2}$ College of Social Work, The Ohio State University, Columbus, Ohio, United States \\ ${ }^{3}$ University of Southern California Keck School of Medicine, Los Angeles, CA, United States \\ ${ }^{4}$ Center for Behavioral Epidemiology and Community Health, San Diego State University, San Diego, CA, United States \\ ${ }^{5}$ School of Social Work, San Diego State University, San Diego, CA, United States \\ ${ }^{6}$ Department of Rehabilitation Medicine, Clinical Center and Office of Behavioral and Social Science Research, National Institutes of Health, \\ Bethesda, MD, United States \\ ${ }^{7}$ Department of Education Studies. University of California, San Diego. La Jolla CA, United States
}

\begin{abstract}
Aims: To test hypotheses involving mechanisms of reinforcement of alcohol behaviors operating in social networks.

Design: Telephone interviews conducted by professional interviewers in Mandarin or Korean or English with first generation Chinese (from Mainland or Taiwan) and Korean immigrants residing using a dual frame stratified sampling design. Combined probability and non-probability approaches for sampling due to the widespread use of cell phones. Interviews were conducted in language of preferences with over 95\% of interviews in Korean or Mandarin.
\end{abstract}

Setting: Residents of three counties with the largest proportions of eligible residents (Los Angeles, Orange, and San Bernardino) were included.

Participants: Adult residents (21 and over) stratified by gender who could be reached by telephone constituted the sample.

Measures: Measures included frequency/amount alcohol consumption drawn from NIAAA standard, a "relax, socialize, have fun with" name generator was used to identify alters. Reinforcers within networks were measured by participant reports of amount of alter drinking, drunkenness, and encouragement to drink, acculturation, and demographic variables were measured by self report.

Findings: Using a random effects approach and controlling for other variables, including drinking in the network, acculturation, Korean/Chinese origin, and demographics, source of immigration, network context, as was and sampling frame, encouragement to drink in the network was related to drinking $(P<.05)$.

Conclusions: Studies of social networks in relation to health behaviors should include measures of actions within networks, especially reinforcers of behaviors, in order to understand the functioning and consequences of networks.

Excessive alcohol consumption has been positively associated with a host of serious health issues, including cancers, cardiovascular disease, damage to specific organs, physical injuries (Cargiulo, 2007), and premature death (Corrao, Bagnardi, Zambon, \& La Vecchia, 2004; Parry, Patra, \& Rehm, 2011). In the U.S., excessive alcohol use is estimated to be responsible for 79,000 deaths annually, and alcohol-related problems cost Americans billions of dollars annually through healthcare costs, lost productivity, and crime-an estimated \$746 per capita in 2006 (Bouchery et. al., 2011).

Understanding the epidemiology of alcohol use is important for both prevention and public policy planning. .

Correspondence: C. Richard Hofstetter, Center for Behavioral Epidemiology and Community Health, 9245 Sky Park Court, STE 230, San Diego, CA, United States 92123-4770. Telephone: 858-901-4356; E-mail: rhofstet@mail.sdsu.edu

Financial support: Supported by grant 1RC1AA018970-01 by NIH/NIAAA to C. Richard Hofstetter and intramural support by the Center for Behavioral and

Epidemiology and Community Health, San Diego State University. Jon-Patrick Allem was supported by a grant from the National Cancer Institute of the National

Institutes of Health under award number T32CA009492.

Declaration of interest: No conflict of interest for all authors

Keywords: Alcohol Behavior, Social Networks, Network Reinforcers, Immigrants, Chinese, Koreans 
The dynamic nature of immigrant populations presents a unique challenge for alcohol researchers interested in understanding the epidemiology and etiology of heavy alcohol use. Earlier studies have reported drinking to be common among Chinese and Koreans in the United States, especially among men (Caetano, Clark, \& Tam, 1998; Lum, Corliss, Mays, Cochran, \& Lui, 2009; Makimoto, 1998). Our study is based on the assumption that firstgeneration immigrants would be partially reliant on social networks to assist with the challenges they face in their new environment (Deri, 2005; Ryan, Sales, Tilki, \& Siara, 2008).

According to the 2000 U.S. Census, immigrants are the fastest-growing segment of the U.S. population, and are expected to comprise $12 \%$ of the total population (33 million) by 2030. Chinese and Korean Americans represent the largest and fourth largest Asian-American populations in the U.S., and increased by $43 \%$ between 2000 and 2010 (Hoeffel. Rastogi, Kim, \& Shahid, 2012). More recently, the 2007 American Community Survey estimated a population of over 4.0 million Chinese and Chinese with other groups (constituting 24\% of Asians in the U.S.) and 1.7 million Koreans and Koreans with other groups (Hoeffel et al., 2012). About 63\% were foreign born and $42 \%$ had limited English proficiency (Kelly, 2010; Kwong \& Wen-Chu Chen, 2010). Several reports suggest that certain Asian groups tend to drink less than Caucasians in the U.S., but that drinking increases with acculturation; however, variance is clear among Asian groups in drinking behavior. For example, Chi and coauthors reported that $14.2 \%$ of Chinese men and $25.8 \%$ of Korean men were "heavy" drinkers, and that drinking was less common among Chinese and Korean females than males (1989, p. 18).

One problem with the extant literature on Asian drinking behavior is its tendency to lump "Asians" into a single group, ignoring the diversity of Asian cultures, a practice which can lead to erroneous conclusions (Unger, 2012). Another has been to conduct interviews in English, despite the fact that many subjects are recent immigrants from nonEnglish speaking societies, and English language skills are highly associated with acculturation.

Immigration is a stress-inducing experience, with some immigrants turning to alcohol in order to cope (Gil, Wagner, \& Vega, 2000; Sinha et al., 2008). Once in the U.S., immigrants tend to live in ethnic enclaves, where social networks may be dense. A social network is typically defined as a set of individuals who are linked by one or more relationships (Hanneman \& Riddle, 2005; Wassermand \& Faust, 1994). Evidence suggests social network characteristics are associated with adoption, continuation, and cessation of health behaviors (Smith \& Christakis, 2008), including health risks, such as alcohol consumption (Rosenquist, Murabito, Fowler, \& Christakis, 2010). However, the mechanisms by which such association might be causal are rarely measured or discussed-an issue that this study addresses.
Research suggests that social network strategies for health promotion may be more efficient than individual-level strategies (Valente, 2010; Valente, Gallaher, \& Mouttapa, 2004); studies often emphasize the structures of networks, as well as the health behaviors associated with these structures (Calafatt et al., 2010; Smith \& Christakis, 2008). A limitation of previous research is that it has not tested the specific mechanisms involved in reinforcing the health risk behaviors that are associated with interaction in network structures (Christakis \& Fowler, 2010).

This study focused on how social networks may exacerbate or ameliorate alcohol consumption among persons subject to the stresses of immigration. Social networks involve regular interaction among individuals, and are defined in terms of the purposes of the interaction-for example, relaxation and fun, gaining advice about specific issues, obtaining information from trusted sources, social support, and so on. Persons bring social norms to their networks and are influenced by social norms learned from others in these networks (Valente, 2010). This study hypothesizes that social interactions, especially modeling and social reinforcement of specific health behaviors, are powerful influences of alcohol risks within social network structures. Socially reinforcing contingencies are technically defined as consequences that subsequently lead to an increase in the same class of behavior. Based on this greater specification of possible mechanisms of social support, the following hypotheses were examined:

1) Amount of alcohol consumption is a function of drinking behaviors of others in one's social networks.

2) Amount of alcohol consumption is a function of encouragement as a reinforcer in one's social networks.

\section{Materials and Methods}

\section{The sample}

A dual sampling frame was used to sample first-generation Korean and Mandarin-speaking Chinese in Los Angeles, Orange, and San Bernardino counties, the three counties with the largest numbers of first-generation Chinese and Korean persons in California. Two major problems were encountered in sampling first-generation Chinese and Korean groups in the greater Los Angeles area. First, each group is dispersed so that they constitute relatively small proportions of the populations within telephone exchanges, meaning that random digit dialing (RDD) is not cost effective in sampling. Second, many persons, especially younger immigrants, are increasingly dependent on cell phones (Blumberg et al., 2011, pp. 11, 13, 17; Blyth, 2008; Couper, 2005; Lynn \& Kaminska, 2010), for which there are no publicly accessible directories available for purposes of sampling.

The first sampling frame was based on random surname samples of listed numbers for Chinese and Korean groups that were purchased for the three counties. The lists of approximately 300 Korean and 300 Chinese surnames encompassed $95 \%$ of all Korean and over $85 \%$ of all Chinese surnames (Lauderdale \& Kestenbaum, 2000; 
Myung, McDonnell, Kazinets, Seo, \& Moskowitz, 2010; Quan et al., 2006; Wong, Palaniappan, \& Lauderdale, 2010). Probability samples of $N=774$ Chinese and $N=$ 861 Koreans were successfully interviewed using the two probability frames.

It was clear, once interviewing had commenced, that the above samples were skewed toward older persons whose lifestyles, including levels of alcohol consumption, were not representative of younger Chinese and Koreans. In other populations, cell phone use and alcohol consumption, especially alcohol abuse, are concentrated among youthful populations, and our data also revealed these tendencies. Another problem is that Chinese and Korean immigrants initially settle in areas of ethnic concentration but then rapidly move to other areas, often in a pattern of upward mobility, and large numbers of other groups are present in these areas (Zhou, 2009).

These considerations led to supplemental non-probability recruitment that included contacts with language schools prominent in Asian communities; radio solicitations; endorsements by ethnic organizations; attendance at ethnic fairs and celebrations, recreation facilities, and educational institutions; solicitations outside Asian grocery stores in Asian shopping centers and Asian shops frequented by Chinese and Koreans; and referrals from would-be survey participants who fell outside the age stratum. Interviews were completed with 410 Chinese and 672 Korean immigrants in the non-probability frame. While nonprobability procedures do not permit estimating population parameters accurately, the data do permit testing hypotheses and controlling statistically for the nature of sampling.

\section{The survey}

Questionnaires designed to measure alcohol consumption and related variables, which had been used successfully in prior studies, were adapted for telephone interviewing. A multistage translation procedure was employed, whereby questions were developed in English, then translated into Mandarin and Korean by bilingual native speakers. An iterative process of focus groups, back translation, and instrument modification was used until accurate meanings of concepts were agreed upon. English, Mandarin, and Korean translations are available on request from the senior author.

Interviewing was conducted by two teams of professional bilingual interviewers, one fluent in Mandarin and English and the other in Korean and English. Both were trained for the questionnaire using role playing and continuing feedback, and were closely supervised by bilingual team leaders. Cooperation rates (percent of eligible participants contacted who completed interviews) were about 55.0\% among Chinese and $65.0 \%$ among Koreans. A project 800 number was installed to answer questions and permit potential respondents to contact project interviewers. All but six interviews were conducted in Korean or Mandarin, as determined by participants’ preferences.
All study procedures were approved by the San Diego State University Institutional Review Board.

\section{Measures}

NIAAA Standard. A wide variety of measures of quantityfrequency of alcohol consumption have been used in published studies. This study used two questions taken from the NIAAA gold standard (National Council on Alcohol Abuse and Alcoholism, October 15-16, 2003) and based on prior research (Rosenquist et al., 2010): "In the last 12 months, how many alcoholic beverages did you drink per week?" and "During the last 12 months, how many alcoholic drinks did you have on a typical day when you drank alcohol?” An ordinal composite scale was coded from the responses: (1) Abstainers (39.1\%) were those who reported not drinking within the prior year. (2) Light drinkers (29.5\%) were those who reported drinking one or two times during the past year and drinking one or two drinks when they drank; or drinking three to12 times during the last year and drinking one drink when they drank; or drinking monthly to twice a week or less and drinking two drinks when drinking; or drinking twice a week and drinking one or two drinks when drinking. (3) Moderate drinkers (22.2\%) were those who reported drinking three to 12 times in the last year and one to four drinks when drinking; or drinking three to 12 times in the last year and twice a month to twice a week and one to four drinks when drinking; or drinking twice a week to every day and one to four drinks when drinking. (4) Heavy drinkers (9.2\%) were those who reported drinking three to 12 times in the last year and five or more drinks when drinking; or drinking twice a month to twice a week and five or more drinks when drinking; or drinking from five or six times a week to every day and five or more drinks when drinking. Chinese and Korean translations are available from the senior author on request.

Network Behaviors. Network linkages (number of alters and frequency of meetings) were measured by responses to two questions: (1) "People sometimes get together with others just to relax, have fun, or socialize. Now, think about all the people you have socialized with, or gotten together with to have fun or relax, during the most recent month [network "alters"]. Just tell me their first name and last initial," and (2) "About how many times have you gotten together with [each alter] during the last six months?" Survey participants (egos) were then asked about the behaviors listed for each alter at each interaction. The total number of alters in a participant's social network was coded zero to four, for up to four mentions. The procedure assumes that the first four mentioned were the most frequent alters, although there may have been additional mentions that were beyond the scope of the project to collect. The final measure was computed by summing the number of meetings each alter reported, where frequency of meetings was capped at 240 for each alter (10 meetings a month for up to four alters), which encompassed over 95\% of participants. The result was then squared to constrain left skewness.

The content of network behaviors regarding alcohol was coded by participants' responses to questions concept- 
ualized as measures of rates of exposure to network variables facilitating alcohol consumption.

a. Percentage of meetings when ego and alter drank together: "On occasions when you got together, did you and [alter] drink alcohol all the time, most of the time, some of the time, or never?” Responses were coded (0 to 4). The measure was computed by multiplying the frequency measure by the number of times reported as drinking ( $1=$ never; $2=$ some times; $3=$ most times; $4=$ all times), and then summing for alters to form a score for each participant. The percentage of total network meetings that involved drinking was then found by dividing times drinking by total number of network meetings, and multiplying the result by 100 . This result was transformed by computing the natural logarithm of the percentage plus 1 to constrain skewness. The higher the percentage, the greater the "dose" of drinking in the network.

b. Percentage of meetings when alter was drunk: "On occasions when you got together, did [alter] become drunk nearly all the time, most of the time, sometimes, or never?” Responses were coded 1 if alter and ego did not drink together, otherwise 2 to 4 for some times, most times, or all times. The measure was computed by multiplying the frequency with which each alter was reported to be drunk by the frequency of meetings. Results were then summed for the number of alters. The percentage of total meetings in which the alters were drunk was found by dividing the number of times drunkenness occurred by the total number of meetings and multiplying the result by 100 , then computing the natural logarithm of the result plus 1 to constrain skewness.

c. Encouragement to drink: "When you were together, did [alter] encourage you to drink, discourage you from drinking, both, or neither?” If the participant chose one of the first two responses (alter had encouraged or discouraged drinking), a follow-up question was asked: "Did [alter] do this nearly always, often, sometimes, or just a few times?" These responses were coded 3,2 , 1 , or 0 . The measure was computed by multiplying the frequency of encouragement to drink by the frequency with which the participant drank, and then summed to measure total encouragement for each alter. The procedure was repeated and summed across alters to measure total discouragement. The summed discouragement score was subtracted from the summed encouragement score across alters, producing a scale running from negative to positive numbers (positive meaning drinking was encouraged, and negative meaning it was discouraged). The sums were then divided by the total meetings, and the result multiplied by 100 and then transformed by computing the natural logarithm of the result plus 1 to constrain skewness.

Acculturation. The Suinn-Lew scale was developed to measure acculturation among Asians in the U.S. and has been used in numerous studies (Suinn, Khoo, \& Ahuna, 1995; Suinn, Rickard-Figueroa, Lew, \& Vigil, 1987). Items were first recoded in an ordinal direction, so that acculturated responses were the numerically largest code. Then, items were standardized (mean $=0, S D=1$ ) so that all had the same variance, and summed to form a composite $(\alpha=.76$, mean $=-0.00, S D=.59)$. The validity of the composite set of items is supported by its use in a series of earlier studies (e.g., Hofstetter et al., 2004, 2010). The higher the number, the more acculturated the respondents. The wording of items can be found in the methodological appendix.

Demographics. Participants' identification as Chinese or Korean, age, gender, household income and education were measured by self report. Subsample (probability or nonprobability) was coded for each participant. Education was calculated as the total years of education in the U.S. plus the non-overlapping years in China or Korea.

\section{Analysis}

All analyses were conducted using STATA (13.1). Distributions of continuous variables were transformed to constrain skewness. Item wording, distributions, and transformations are reported in Tables 1 and 2. Hypotheses were tested by regressing the drinking scale based on two questions from the NIAAA standard six items (National Council on Alcohol Abuse and Alcoholism, 2003) measuring frequency and number of drinks consumed. Controls for the number of network linkages, age, gender, education, acculturation, ethnicity (Chinese or Korean), and subsample (probability or non-probability) were included using ordinal logistic regression in the analysis. Analyses were replicated using the missing data imputation, using the STATA MI procedure with a normal distribution of error assumption (MVN) and 100 imputations based on the covariance structure of the data and random assignment of error (StataCorp, 2013).

\section{Results}

\section{Demographics}

All study participants were born in Korea, mainland China, or Taiwan. Of the Chinese participants, $56.6 \%$ were born in mainland China, and $43.1 \%$ were born in Taiwan. About $95.7 \%$ of Chinese and $96.4 \%$ of Korean participants were interviewed in Mandarin and in Korean, respectively, by personal preference, while four Chinese and five Koreans were interviewed partially in Mandarin or Korean and partially in English, according to their preferences. About $4.3 \%$ of Chinese and $3.6 \%$ of Koreans preferred to be interviewed in English. Only 10.2\% of Chinese and 22.0\% of Koreans reported having been born in rural places in mainland China, Taiwan, or Korea.

According to data in Table 1, there were no statistically significant differences $(P>.05)$ between Chinese and Korean immigrants in gender (50.1\% vs. 53.2\%), age (43.6 years vs. 42.9 years), age at time of immigration (28.0 years vs. 29.0 years), being married or cohabiting (66.6\% 
Table 1

Sample characteristics by total sample, national origin, and sample frame

\begin{tabular}{|c|c|c|c|c|c|c|}
\hline \multirow[b]{2}{*}{ Demographics } & \multicolumn{2}{|c|}{ Chinese } & \multicolumn{2}{|c|}{ Korean } & \multicolumn{2}{|c|}{ Differences } \\
\hline & Mean/\% & $S D$ & Mean/\% & $S D$ & $t$ & $\boldsymbol{P}<$ \\
\hline Male & $50.1 \%$ & & $53.2 \%$ & & -1.19 & 0.233 \\
\hline Age & 43.6 & 14.2 & 42.9 & 14.8 & 1.23 & 0.217 \\
\hline Education & 15.3 & 3.2 & 15.5 & 2.8 & -2.06 & 0.040 \\
\hline Age at immigration & 28.0 & 12.7 & 29.0 & 52.8 & -0.668 & 0.504 \\
\hline Married & $66.6 \%$ & & $64.8 \%$ & & 0.971 & 0.332 \\
\hline U.S. citizen & $65.4 \%$ & & $43.9 \%$ & & 11.39 & 0.001 \\
\hline Probability sample & $65.3 \%$ & & $56.2 \%$ & & 4.84 & 0.001 \\
\hline Acculturation & -0.03 & 1.00 & 0.02 & 1.00 & -1.37 & 0.172 \\
\hline \multicolumn{7}{|l|}{ Network Measures: } \\
\hline Network links & 174.3 & 204.6 & 275.6 & 239.7 & -11.6 & 0.000 \\
\hline Percent links both drinking & 12.2 & 19.6 & 19.7 & 30.8 & -6.6 & 0.000 \\
\hline Percent links alter drunk & 2.6 & 6.4 & 7.7 & 14.5 & -10.0 & 0.000 \\
\hline \multirow[t]{3}{*}{ Percent links encourage drinking } & 0.06 & 0.40 & 0.58 & 1.34 & -12.9 & 0.000 \\
\hline & \multicolumn{2}{|c|}{ Non-Probability } & \multicolumn{2}{|c|}{ Probability } & \multicolumn{2}{|c|}{ Differences } \\
\hline & Mean/\% & $S D$ & Mean/\% & $S D$ & $t$ & $\boldsymbol{P}<$ \\
\hline Male & $60.6 \%$ & 48.9 & 46.7 & 50.0 & 7.19 & 0.001 \\
\hline Age & 36.8 & 10.8 & 47.4 & 15.1 & -20.06 & 0.001 \\
\hline Education & 15.8 & 2.3 & 15.2 & 3.3 & 5.28 & 0.001 \\
\hline Age at immigration & 24.9 & 9.7 & 30.9 & 51.6 & -3.76 & 0.001 \\
\hline Married & $53.0 \%$ & & $73.9 \%$ & & -11.51 & 0.001 \\
\hline U.S. citizen & $39.0 \%$ & & $62.7 \%$ & & -12.40 & 0.001 \\
\hline Acculturation & 0.2 & 0.9 & -1.0 & 1.1 & 6.56 & 0.001 \\
\hline \multicolumn{7}{|l|}{ Network Measures: } \\
\hline Network links & 271.3 & 246.0 & 199.0 & 213.6 & 9.24 & 0.001 \\
\hline Percent links both drinking & 17.6 & 26.9 & 16.1 & 27.4 & 1.32 & 0.907 \\
\hline Percent links alter drunk & 7.0 & 13.0 & 4.5 & 11.4 & 4.98 & 0.001 \\
\hline Percent links encourage drinking & 0.6 & 1.3 & 0.2 & 0.9 & 7.87 & 0.001 \\
\hline
\end{tabular}

vs. $64.8 \%$ ), and acculturation (-.03 vs. .02). Statistically significant differences existed between the probability and non-probability samples for all demographic variables $(P<$ $.05)$ : more males were included in the non-probability sample (60.6\% vs. $46.7 \%)$, fewer were married (53.0\% vs. 73.9\%), and fewer were U.S. citizens (39.0\% vs. 62.7\%). Participants in the non-probability sample were also younger (36.8 years vs. 47.4 years), better educated (15.8 years vs. 15.3 years), younger at time of immigration (24.9 years vs. 30.9 years), and less acculturated (0.2 vs. 1.1$)$.

\section{Network Linkages}

Chinese immigrants reported fewer network linkages than Koreans (174.3 vs. 275.6), and lower rates of network linkages in which both persons drank alcohol (12.2\% vs. $19.7 \%$ ), the alter became drunk (2.6\% vs. $7.7 \%$ ), and/or the alter encouraged drinking (.06\% vs. .58\%). In comparison to persons in the probability sample, persons in the non- probability sample reported more network linkages (271.3 vs. 199.0), and a larger rate of linkages in which alters were drunk (7.0 vs. 4.5) and alters encouraged the survey participant to drink (0.6 vs. 0.2 ). There was no statistically significant $(P>.05)$ association between sampling frames in the rate of occasions in which both persons drank alcohol (17.6 vs. 16.1).

\section{Origin of Immigration}

Results in Table 1 suggest that it is important to assess alcohol consumption by origin of immigration (Chinese vs. Korean) and sample frame (non-probability vs. probability). It is also useful to determine any significant alcohol consumption differences among Chinese from Mainland China and those from Taiwan, given the differences in living conditions between the two groups. Table 2 presents differences in alcohol consumption by nation of origin, and differences by sampling frame within 
nationalities, which were statistically significant $(P<.001$ by Fisher's exact tests).

In general, Korean immigrants were less likely to be abstainers and more likely to be moderate or heavy drinkers than Chinese in each group $(P<.001)$. Among Chinese, $52.7 \%$ were abstainers and $1.9 \%$ were heavy drinkers, compared to $28.4 \%$ of Koreans who were abstainers and $9.2 \%$ who were heavy drinkers. Similar differentials between Chinese and Koreans were reported in the nonprobability analysis (38.4\% vs. $15.2 \%$ abstainers, and 3.1\% vs. $22.8 \%$ heavy drinkers, respectively, $P<.001$ ) and the probability analysis $(59.8 \%$ vs. $38.2 \%$ abstainers and $1.3 \%$ vs. $9.2 \%$ heavy drinkers, respectively, $P<.001$ ). However, the non-probability sample reported fewer abstainers and more heavy drinkers than the probability sample $(P<.001)$. Among Chinese, slightly fewer of those from Taiwan than those from the Mainland reported abstention (50.0\% vs. $54.7 \%)$ or heavy drinking ( $2.4 \%$ vs. $1.5 \%)$, although the differences were not statistically significant $(P>.05)$.

\section{Bivariate and Multivariate Analyses of Drinking}

Multivariate ordinal analysis procedures and bivariate analyses were used to evaluate hypotheses and are presented in Table 3, below. Data in Table 2 suggest the need to pay particular attention to the origin (Chinese vs. Korean) of immigrants as well as the sampling frame (probability vs. non-probability). For this reason, sample (probability vs. non-probability) was controlled by including the sample frame as a covariate in analyses, and analyses were also replicated by subsetting for sampling frame.

Bivariate analysis in Table 3 provides support for each of the hypotheses $(P<.05)$. The odds of drinking increase with the number of network linkages, the rate of both ego (survey participant) and alter (person reported about) drinking, the rate that alter is intoxicated in linkages, and the rate that alter encouraged ego to drink in network linkages. Data in Table 1 suggested that alter and ego drinking together, alter intoxication, and encouragement of ego drinking occur infrequently, but also that these behaviors are associated with increased drinking by survey participants. These data also suggest that male gender, education, acculturation and being Korean is associated with increased drinking, while older age and being in the probability sample is associated with decreasing drinking.

The multivariate analysis generally supports the bivariate analyses, although the effects of collinearity are clear. Most importantly, two of the network variables-alter and ego both drinking, and ego being encouraged by alter to drink-were associated with drinking in the predicted direction, after network size, rate of alter drunkenness, and other covariates were controlled, supporting hypotheses 1 and 2. Being male, in the probability sample, and Korean were associated with increased drinking, while being older and in the probability sample were associated with diminished drinking. Education and acculturation were no longer related to drinking in a statistically significant way $(P>.05)$. The rate of alter drunkenness was associated with diminished drinking in the multivariate analyses, possibly due to collinearity with the other network drinking behaviors.

Table 3 also presents logistic regressions by nationality. With several exceptions, the two sets of analysis replicate the preceding results. Size of network, drinking together in networks, and encouragement to drink (among Koreans, but not statistically significantly among Chinese, $P<.05$ ) are associated with drinking, as is male gender. Alter drunkenness, being older, and probability sample frame were all associated with diminished drinking, controlling for other covariates among both Koreans and Chinese. Slight differences appeared between Chinese and Koreans. Education was associated positively with drinking among Chinese and negatively among Koreans (non-significant, $P$ $>.05$ ), although the odds ratios were small. Acculturation was not statistically significantly associated with drinking among Chinese $(P>.05)$ but was associated negatively with drinking among Koreans $(P<.05)$.

Table 2

Distribution of alcohol use by nationality, sampling frame, and mainland vs. Taiwanese-Chinese origin ${ }^{a}$

\begin{tabular}{|c|c|c|c|c|c|c|c|c|}
\hline \multirow{3}{*}{$\begin{array}{l}\text { Alcohol } \\
\text { Consumption }\end{array}$} & \multicolumn{8}{|c|}{ Type of Sample } \\
\hline & \multicolumn{2}{|c|}{$\begin{array}{c}\text { Nationality } \\
\text { Samples }\end{array}$} & \multicolumn{2}{|c|}{$\begin{array}{c}\text { Non-Probability } \\
\text { Samples } \\
\text { Nationality }\end{array}$} & \multicolumn{2}{|c|}{$\begin{array}{c}\text { Probability Samples } \\
\text { Nationality }\end{array}$} & \multicolumn{2}{|c|}{$\begin{array}{c}\text { Chinese Origin } \\
\text { Samples }\end{array}$} \\
\hline & Chinese & Korean & Chinese & Korean & Chinese & Korean & Taiwan & Mainland \\
\hline Abstain & $52.7 \%$ & $28.4 \%$ & $38.4 \%$ & $15.2 \%$ & $59.8 \%$ & $38.2 \%$ & $50.0 \%$ & $54.7 \%$ \\
\hline Light use & 31.6 & 29.5 & 36.5 & 25.3 & 29.1 & 29.7 & 31.0 & 32.0 \\
\hline Moderate use & 13.9 & 22.2 & 22.0 & 36.7 & 9.8 & 22.9 & 16.7 & 11.8 \\
\hline Heavy use & 1.9 & 9.2 & 3.1 & 22.8 & 1.3 & 9.2 & 2.4 & 1.5 \\
\hline Total & $100.0 \%$ & $100.0 \%$ & $100.0 \%$ & $100.0 \%$ & $100.0 \%$ & $100.0 \%$ & $100.0 \%$ & $100.0 \%$ \\
\hline \multirow[t]{2}{*}{$(N)$} & $(1071)$ & $(1362)$ & (359) & $(580)$ & (712) & (781) & $(462)$ & (609) \\
\hline & \multicolumn{2}{|c|}{ Fisher's Exact $P<.001$} & \multicolumn{2}{|c|}{ Fisher's Exact $P<.001$} & \multicolumn{2}{|c|}{ Fisher's Exact $P<.001$} & \multicolumn{2}{|c|}{ Fisher's Exact $P<.079$} \\
\hline
\end{tabular}

\footnotetext{
${ }^{a}$ Numbers are percentages of alcohol consumption by nationality, sample frame, and origin of Chinese immigrants. Missing data were deleted.
} 
Table 3

Ordinal regression of alcohol consumption on network and selected variables among First-Generation Korean-and Mandarinspeaking Chinese immigrants in Greater Los Angeles by combined nationalities, nationalities, sampling frame, and bivariate associations $^{a}$

\begin{tabular}{|c|c|c|c|c|c|c|}
\hline \multirow[b]{2}{*}{ Predictor } & \multirow[b]{2}{*}{ OR } & \multicolumn{2}{|c|}{$\begin{array}{c}\begin{array}{c}\text { Total Sample } \\
\text { Multivariable Analysis }\end{array} \\
\mathbf{9 5 \%} \text { CI } \\
\end{array}$} & \multirow[b]{2}{*}{ OR } & \multicolumn{2}{|c|}{$\begin{array}{c}\begin{array}{c}\text { Total Sample } \\
\text { Bivariate Analysis }\end{array} \\
95 \% \mathrm{CI} \\
\end{array}$} \\
\hline & & Lower & Upper & & Lower & Upper \\
\hline Number network links & 1.025 & 1.012 & 1.039 & 1.053 & 1.044 & 1.063 \\
\hline Percent of both drink when together & 3.168 & 2.410 & 4.165 & 2.174 & 2.045 & 2.316 \\
\hline Percent times alter drunk & 0.476 & 0.347 & 0.654 & 2.254 & 2.092 & 2.428 \\
\hline Percent times encourage ego to drink & 1.222 & 1.146 & 1.303 & 1.588 & 1.498 & 1.683 \\
\hline Gender (male) & 2.179 & 1.815 & 2.615 & 3.437 & 2.951 & 4.003 \\
\hline Years education & 1.000 & 0.999 & 1.002 & 1.003 & 1.002 & 1.004 \\
\hline Age & 0.335 & 0.247 & 0.454 & 0.146 & 0.116 & 0.185 \\
\hline Acculturation & 0.946 & 0.859 & 1.043 & 1.446 & 1.343 & 1.558 \\
\hline Sample (probability) & 0.697 & 0.582 & 0.836 & 0.331 & 0.284 & 0.386 \\
\hline \multirow[t]{8}{*}{ Nationality (Korean) } & 1.894 & 1.570 & 2.284 & 3.372 & 2.893 & 2.933 \\
\hline & -2.467 & -3.657 & -1.277 & & & \\
\hline & -0.591 & -1.774 & 0.590 & & & \\
\hline & 1.638 & 0.447 & 2.830 & & & \\
\hline & \multicolumn{6}{|c|}{$\begin{array}{l}\text { Pseudo } R^{2}=.20 \text {, Wald Chi Square =828.82, } \\
P<.001\end{array}$} \\
\hline & & \multicolumn{2}{|c|}{ Chinese } & & \multicolumn{2}{|c|}{ Korean } \\
\hline & & \multicolumn{2}{|c|}{$95 \%$ CI } & & \multicolumn{2}{|c|}{$95 \%$ CI } \\
\hline & OR & Lower & Upper & OR & Lower & Upper \\
\hline Number network links & 1.022 & 1.000 & 1.045 & 1.026 & 1.008 & 1.044 \\
\hline Percent of both drink when together & 6.273 & 2.902 & 13.561 & 2.786 & 2.100 & 3.697 \\
\hline Percent times alter drunk & 0.223 & 0.093 & 0.534 & 0.551 & 0.396 & 0.767 \\
\hline Percent times encourage ego to drink & 1.140 & 0.909 & 1.429 & 1.221 & 1.143 & 1.303 \\
\hline Gender (male) & 2.674 & 2.011 & 3.555 & 1.885 & 1.487 & 2.390 \\
\hline Years education & 1.002 & 1.000 & 1.003 & 0.999 & 0.998 & 1.001 \\
\hline Age & 0.340 & 0.212 & 0.544 & 0.319 & 0.210 & 0.484 \\
\hline Acculturation & 1.049 & 0.886 & 1.243 & 0.876 & 0.775 & 0.990 \\
\hline \multirow[t]{8}{*}{ Sample (probability) } & 0.644 & 0.475 & 0.872 & 0.697 & 0.553 & 0.878 \\
\hline & -2.828 & -4.623 & -1.032 & -4.149 & -5.841 & -2.458 \\
\hline & -0.619 & -2.413 & 1.174 & -2.459 & -4.136 & -0.782 \\
\hline & 2.145 & 0.235 & 4.055 & -0.339 & -2.007 & 1.329 \\
\hline & \multicolumn{3}{|c|}{$\begin{array}{l}\text { Pseudo } R^{2}=.16 \text {, Wald Chi Square }=220.21 \text {, } \\
P<.001\end{array}$} & \multicolumn{3}{|c|}{$\begin{array}{l}\text { Pseudo } R^{2}=.15 \text {, Wald Chi Square }=479.24 \text {, } \\
P<.001\end{array}$} \\
\hline & & \multicolumn{2}{|c|}{$\begin{array}{c}\text { Probability Sampling } \\
\text { Frame }\end{array}$} & & \multicolumn{2}{|c|}{$\begin{array}{l}\text { Non-Probability } \\
\text { Sampling Frame }\end{array}$} \\
\hline & & \multicolumn{2}{|c|}{$95 \% \mathrm{CI}$} & & \multicolumn{2}{|c|}{$95 \% \mathrm{CI}$} \\
\hline & OR & Lower & Upper & OR & Lower & Upper \\
\hline Number network links & 1.016 & 0.998 & 1.034 & 1.035 & 1.015 & 1.056 \\
\hline Percent of both drink when together & 3.514 & 2.305 & 5.358 & 3.015 & 2.095 & 4.340 \\
\hline Percent times alter drunk & 0.441 & 0.270 & 0.717 & 0.488 & 0.319 & 0.746 \\
\hline Percent times encourage ego to drink & 1.204 & 1.088 & 1.332 & 1.225 & 1.126 & 1.332 \\
\hline Gender (male) & 2.017 & 1.569 & 2.591 & 2.435 & 1.857 & 3.195 \\
\hline Years education & 1.000 & 0.999 & 1.002 & 1.001 & 0.999 & 1.003 \\
\hline Age & 0.303 & 0.201 & 0.458 & 0.379 & 0.241 & 0.598 \\
\hline Acculturation & 0.881 & 0.776 & 1.001 & 1.050 & 0.897 & 1.229 \\
\hline \multirow[t]{5}{*}{ Nationality (Korean) } & 1.829 & 1.422 & 2.352 & 1.889 & 1.415 & 2.523 \\
\hline & -2.716 & -4.369 & -1.063 & -1.683 & -3.439 & 0.072 \\
\hline & -0.836 & -2.475 & 0.802 & 0.213 & -1.544 & 1.970 \\
\hline & 1.316 & -0.339 & 2.972 & 2.509 & 0.739 & 4.279 \\
\hline & \multicolumn{3}{|c|}{$\begin{array}{l}\text { Pseudo } R^{2}=.16 \text {, Wald Chi Square }=400.87 \text {, } \\
P<.001\end{array}$} & \multicolumn{3}{|c|}{$\begin{array}{l}\text { Pseudo } R^{2}=.18 \text {, Wald Chi Square }=364.35 \text {, } \\
P<.001\end{array}$} \\
\hline
\end{tabular}

${ }^{\text {a }}$ Numbers in cells are OLS regression coefficients and associated 95\% confidence intervals from regressing social network and other predictors on the multivariate ordinal drinking measure for the total sample, the Chinese and Korean immigrant groups, sampling frames, and bivariate associations between predictors and drinking. The drinking measure is a scale drawn from two items in the NIAAA six-item standard (National Institute of Alcohol Abuse and Alcoholism, October 15-16, 2003). Percent of network links in which both drink, percent links in which the alter was drunk, percent links in which alter encouraged drinking, and age were transformed using the natural log to constrain right skewness. Number of network links and years of formal education were transformed by squaring the raw scores to constrain left skews. 
Evidence that findings are not simply a function of artifacts generated by different groups and different sampling frames is presented in the bottom section of Table 3 . Ordinal regressions showed that network rates were related to drinking, as in the proceeding sections of Table 3, regardless of sample frame. The partial associations between education and acculturation and drinking were not statistically significant $(P>.05)$ in either sampling frame. Male Koreans drank more in both sample frames than female Koreans $(P<.05)$.

Adjusted odds ratios are not identical from one subset of data to another, but the signs of the odds ratios are identical in every set of regressions involving networking variables, although differences between the bivariate and multivariate analyses suggest that multicollinearity is at work, an assumption supported by bivariate correlations among the network variables. These results support the conclusion that the mechanisms involved in the network reinforcement of drinking and other predictors are not simply due to artifacts of origin of immigration or either of the dual sampling frames. The consistency of associations between network variables and drinking in the several subsamples in Table 3 increase confirmation of the hypotheses.

Finally, missing data were imputed using the MI procedure in STATA 13 using 100 imputations in each analysis. Results are not reported here, but replication of analyses suggests that results are not due to patterns of missing data.

\section{Discussion}

This study demonstrated the importance of considering social networks when seeking to understand alcohol consumption among two rapidly growing first-generation immigrant populations. Bivariate and multivariate partial associations demonstrate that positive reinforcement, sharing drinks, and encouragement to drink were consistently associated with alcohol consumption, after covariates were controlled, in large population-based surveys of immigrants from China and Korea. Findings were replicated when data were subset by nationality groups and sample frames. Encouragement to drink by others, assumed to be a key mechanism, was statistically significantly associated with drinking in a bivariate analysis and multivariate analyses, with one exception (the multivariate analysis of the Chinese subsample, where the non-significant finding involved an odds ratio in the hypothesized direction). Similarly, drunkenness of alters was strongly associated with drinking in bivariate analyses, but reversed direction in the multivariate analyses, a reversal likely due to collinearity with other network measures.

Beyond network variables, nationality, gender, and age were strongly and consistently related to alcohol behavior. First-generation immigrants undergo rapid changes in their social environments and in their social networks. Using two indicators from NIAAA-endorsed measures which focus on the frequency and amount of alcohol consumption, the study controlled for cultural differences, and the results suggest how environmental variables may influence individual alcohol behavior.

Comparisons with odds ratios indicated general agreement in direction of associations between drinking and network and other predictors, regardless of group, with only one minor deviation of sign (between acculturation and drinking among the probability sample, and education and drinking among the Korean subsample, but neither deviation was statistically significant). Although odds ratios varied somewhat, the direction of associations were consistent between the total sample, Chinese and Korean subsamples, and probability and non-probability subsamples.

First-generation Chinese and Koreans were selected for analysis because both are rapidly growing populations, and disruptions of existing social networks by immigration permitted collection of data from persons undergoing dramatic change and consequent disruptions in their lives (Hoeffel et al., 2012; Zhou, 2009, p. 223-235). These types of life events are associated with greater alcohol consumption among general populations in numerous studies, although the associations with alcohol may be mitigated by buffering factors, such as social support and coping resources (Veenstra et al., 2006) or exacerbated by poverty, racism, and other hardships (Gee, Spencer, Chen, Yip, \& Takeuchi, 2007; Stockdale et al., 2007). Mulia and co-authors (2008a, b) reported that adverse experiences, such as poverty, racism, and other disadvantages, were associated with at-risk drinking and problem drinking among both minorities and whites. No association between stress and drinking was found in our data, so that measure was dropped. It is likely that collinearity with other predictors, especially education, income, and acculturation, was responsible for this finding.

These data contribute to idea that a "social contagion" effect is involved in network public-health risk behaviors (Christakis \& Fowler, 2010) and suggest how social norms in broader cultures may influence individual health behaviors, and may also be susceptible to influence by public policy at a higher level of aggregation (Glass \& McAtee, 2006; Hovell, Wahlgren, \& Adams, 2009). The data support the hypothesis that widespread norms in societies, which may be influenced by public policy, in turn influence behaviors within social networks. The greater familiarity, trust, and intimacy that develop within social networks may enhance the extent of influence that network interaction has in shaping health behaviors involving alcohol, smoking, or other hazards.

While social networks are not the only influence on behavior, they are important, as other research has suggested. So, too, are the more direct influences of public policy, such as enforcement of laws at the various levels of government; group subcultures and experiences; and many other aspects of the environment that influence individuals and may be carried into a social network (Valente, 2010). 


\section{Limitations}

One unresolved problem with social network analysis is that of homophily (Aral, Muchnik, \& Sundararajan, 2009; McPherson, Smith-Lovin, \& Cook, 2001, Simons-Morton \& Farhat, 2010; Van der Weele, 2011); that is, do drinkers associate with other drinkers, or do people who join social networks acquire the behaviors of others in the network through interaction? While no cross-sectional analysis can bring rigorous evidence to bear on this issue, our data show that persons who report network behaviors that encourage use of alcohol increase their consumption of alcohol to a greater degree than those who do not, after controlling for other network variables including network size and drinking with others. However, network reinforcer associations were controlled, using the number of network linkages, and behaviors that were assumed to reinforce drinking were consistently associated with alcohol consumption. Acculturation, age, gender, and education, as well as national origin and sampling frames, were controlled statistically. Data were collected by survey interviewing by telephone and therefore relied on selfreport, which is the basis of much alcohol research but is subject to a variety of biases.

\section{Future Studies}

Future studies should explore the association between changes in network behaviors and in alcohol consumption, using a longitudinal approach. Circumstances of immigration vary in many ways, so that conclusions would be bolstered by including more diverse groups of immigrants who face more varied types of problems in American society. Refocusing research to smaller, more narrowly defined and spatially constrained groups may be productive in future studies involving social networks and alcohol consumption, although this study has provided initial evidence that focusing on network mechanisms among two immigrant groups further specifies the way networks function, in a broader, societal-level context, to influence alcohol behaviors. Studying immigrant population requires using appropriate languages according to the preference of respondents, as well as consideration of problems with sampling for surveys likely to be at least partially conducted using cell phones.

\section{Acknowledgements:}

This project was supported by grant 1RC1AA018970-01 by NIH/NIAAA to C. Richard Hofstetter and intramural support by the Center for Behavioral and Epidemiology and Community Health, San Diego State University. JonPatrick Allem was supported by a grant from the National Cancer Institute of the National Institutes of Health under award number T32CA009492. Journal referees and editors were particularly helpful in revisions to this paper, although the authors are responsible for any errors that may appear.

\section{References}

Aral, S., Muchnik, L., \& Sundararajan, A. (2009). Distinguishing influence-based contagion from homophily-driven diffusion in dynamic networks. Proceedings of the National Academy of Sciences, 106(51), 21544-21549.

Blumberg, S. J., Luke, J. V., Ganesh, N., Davern, M., Boudreaux, M., \& Soderberg, K. (2011). Wireless substitution: State-level estimates from the National Health Interview Survey, January 2007-June 2010. (DHHS Publication No. PHS CS220921). Hyattsville, MD, United States: National Center for Health Statistics.

Blyth, B. (2008). Mixed mode: The only 'fitness' regime? International Journal of Market Research, 50(2), 241266.

Bouchery, E. E., Henrick, M., Harwood, J., Sacks, J. J., Simon, C. J., \& Brewer, R. D. (2011). Economic costs of excessive alcohol consumption in the U.S., 2006. American Journal of Preventive Medicine, 41(5), 516524. doi: 10.1016/j.amepre.2011.06.045

Calafatt, A., Calafatt, B., Juant, M., Mendest, F., Kokkevi, A., Blay, N, . . Duch, M. A. (2010). The influence of personal networks on the use and abuse of alcohol and drugs. Adicciones, 22(2), 147-154.

Caetano, R., Clark, C. L., \& Tam, T. (1998). Alcohol consumption among racial/ethnic minorities. Alcohol Health and Research World, 22(4), 233-241.

Cargiulo, T. (2007). Understanding the health impact of alcohol dependence. American Journal of HealthSystem Pharmacy, 64(5 Supplement 3), S5-S11.

Chi, I., Lubben, J. E., \& Kitano, H. H. (1989). Differences in drinking behavior among three Asian-American groups. Journal of Studies on Alcohol, 50(1), 15-23.

Christakis, N. A., \& Fowler, J. H. (2010). Contagion in prescribing behavior among networks of doctors. Marketing Science, 30(2), 213-216.

Corrao, G., Bagnardi, V., Zambon, A., \& La Vecchia, C. (2004). A meta-analysis of alcohol consumption and the risk of 15 diseases. Preventive Medicine, 38(5), 613-619.

Couper, M. P. (2005). Technology trends in survey data collection. Social Science Computer Review, 23(4), 486-501.

Deri, C. (2005). Social networks and health service utilization. Journal of Health Economics, 24(6), 10761107.

Gee, G. C., Spencer, M., Chen, J., Yip, T., \& Takeuchi, D. T. (2007). The association between self-reported racial discrimination and 12-month DSM-IV mental disorders among Asian Americans nationwide. Social Science \& Medicine, 64(10), 1984-1996.

Gil, A. G., Wagner, E. F., \& Vega, W. A. (2000). Acculturation, familism, and alcohol use among Latino adolescent males: Longitudinal relations. Journal of Community Psychology, 28(4), 443-458.

Glass, T. A., \& McAtee, M. J. (2006). Behavioral science at the crossroads in public health: Extending horizons, envisioning the future. Social Science \& Medicine, 62(7), 1650-1671. 
Hanneman, R. A., \& Riddle, M. (2005). Introduction to social network methods. Retrieved from http://faculty.ucr.edu/ hanneman/. Accessed January 15, 2013.

Hoeffel E. M, Rastogi S, Kim M. O., \& Shahid H. (2012). The Asian population 2010. Census 2010 Brief. U.S. Census Bureau. Retrieved from http://www.census.gov/prod/cen2010/briefs/c2010br11.pdf . Accessed March 13, 2013.

Hofstetter, C. R., Hovell, M. F., Irvin, V. L., Ayers, J. W., Hughes, S.C., \& Kang, S. (2010). It's others, not the police: Smoking, reprimand, and fines among adults of Korean descent in California. Health Psychology, 29(3), 255-261.

Hofstetter, C. R., Hovell, M. F., Jung, K. R., Raman, R., Irvin, V., \& Ni, R. (2007). The first puff: Forces in smoking initiation among Californians of Korean descent. Nicotine \& Tobacco Research, 9(12), 12771286.

Hofstetter, C. R., Hovell, M. F., Lee, J., Zakarian, J., Park, H., Paik, H.Y., \& Irvin, V. (2004). Tobacco use and acculturation among Californians of Korean descent: A behavioral epidemiological analysis. Nicotine \& Tobacco Research, 6(3), 481-489.

Hovell, M., Wahlgren, D., \& Adams, M. (2009). The logical and empirical basis for the behavioral ecological model. In R. J. Di Clement, R. A. Crosby, \& M. C. Kegler (Eds.), Emerging theories in health promotion practice and research: Strategies for improving public health, 2nd edition (415-449). San Francisco: Jossey-Bass.

Kelly, K. (2010). Demographic overview: Diverse, growing, and ever-changing. In E. W. -C. Chen \& G. J. Yoo (Eds.), Encyclopedia of Asian American issues today (Vol. 1, 3-14). Santa Barbara, CA, United States: Greenwood Press.

Kwong, P., \& Wen-Chu Chen, E. (2010). Chinese Americans. In E. W.-C. Chen \& G. J. Yoo (Eds.), Encyclopedia of Asian American issues today (Vol. 1, 15-23). Santa Barbara, CA, United States: Greenwood Press.

Lauderdale, D. S., \& Kestenbaum, B. (2000). Asian American ethnic identification by surname. Population Research and Policy Review, 19(3), 283300.

Lum, C., Corliss, H. L., Mays, V. M., Cochran, S. D., \& Lui, C. K. (2009). Differences in the drinking behaviors of Chinese, Filipino, Korean, and Vietnamese college students. Journal of Studies on Alcohol and Drugs, 70(4), 568-574.

Lynn, P., \& Kaminska, O. (2010). The impact of mobile phones on survey measurement error. Institute for Social and Economic research paper. Retrieved from https://www.iser.essex.ac.uk/files/iser_working_paper s/2011-07.pdf. Accessed February 9, 2013.

Makimoto, K. (1998). Drinking patterns and drinking problems among Asian-Americans and Pacific Islanders. Alcohol Health and Research World, 22, 270-275.

McPherson, M., Smith-Lovin, L., \& Cook, J. M. (2001). Birds of a feather: Homophily in social networks. Annual Review of Sociology, 27, 415-444.
Mulia, N., Schmidt, L., Bond, J., Jacobs, L., \& Korcha, R. (2008a). Stress, social support and problem drinking among women in poverty. Addiction, 103(8), 12831293.

Mulia, N., Ye, Y., Zemore, S. E., \& Greenfield, T. K. (2008b). Social disadvantage, stress, and alcohol use among black, Hispanic, and white Americans: Findings from the 2005 U.S. National Alcohol Survey. Journal of Studies on Alcohol and Drugs, 69(6), 824833.

Myung, S. K., McDonnell, D. D., Kazinets, G., Seo, H. G., \& Moskowitz, J. M. (2010). Relationships between household smoking restrictions and intention to quit smoking among Korean American male smokers in California. Journal of Korean Medical Science, 25(2), 245-250.

National Council on Alcohol Abuse and Alcoholism. (2003). Recommended sets of alcohol consumption questions. Retrieved from http://www.niaaa.nih.gov/ research/guidelines-and-resources/recommendedalcohol-questions. Accessed March 1, 2012.

Parry, C. D., Patra, J., \& Rehm, J. (2011). Alcohol consumption and non-communicable diseases: Epidemiology and policy implications. Addiction, 106, 1718-1724. doi:10.1111/j.1360-0443.2011.03605x

Quan, H., Wang, F., Schopflocher, D., Norris, C., Galbraith, P. D., Faris, P., . . . Ghali, W. A. (2006). Development and validation of a surname list to define Chinese ethnicity. Medical Care, 328-333.

Rosenquist, J. N., Murabito, J., Fowler, J. H., \& Christakis, N. A. (2010). The spread of alcohol consumption behavior in a large social network. Annals of Internal Medicine, 152(7), 426-433.

Ryan, L., Sales, R., Tilki, M., \& Siara, B. (2008). Social networks, social support and social capital: The experiences of recent Polish migrants in London. Sociology, 42(4), 672-690.

Simons-Morton, B., \& Farhat, T. (2010). Recent findings on peer group influences on adolescent substance use. The Journal of Primary Prevention, 31(4), 191-208. doi:10.1007/s10935-010-0220-x

Sinha, R., Fox, H. C., Hong, K. A., Bergquist, K., Bhagwagar, Z., \& Siedlarz, K. M. (2008). Enhanced negative emotion and alcohol craving, and altered physiological responses following stress and cue exposure in alcohol dependent individuals. Neuropsychopharmacology, 34(5), 1198-1208.

Smith, K. P., \& Christakis, N. A. (2008). Social networks and health. Annual Review of Sociology, 34, 405-429.

StataCorp. (2013). Stata: Release 12. Multiple-Imputation Reference Manual (Release 12). College Station, TX: StataCorp LP.

Stockdale, S. E., Wells, K. B., Tang, L., Belin, T. R., Zhang, L., \& Sherbourne, C. D. (2007). The importance of social context: Neighborhood stressors, stress-buffering mechanisms, and alcohol, drug, and mental health disorders. Social Science \& Medicine, 65(9), 1867-1881.

Suinn, R. M., Khoo, R.-F., \& Ahuna, C. (1995). The SuinnLew Asian self-identity acculturation to U.S. society scale: Cross-cultural information. Journal of 
Multicultural Counseling \& Development, 23, 139148.

Suinn, R. M., Rickard-Figueroa, R. M., Lew, K. S., \& Vigil, P. (1987). The Suinn-Lew Asian self-identity acculturation to U.S. society scale: An initial report. Educational \& Psychological Measurement, 47, 401407.

Unger, J. B. (2012). The most critical unresolved issues associated with race, ethnicity, culture, and substance use. Substance Use \& Misuse, 47(4), 390-395.

Valente, T. W. (2010). Social networks and health: Models, methods, and applications. New York, NY, United States: Oxford University Press.

Valente, T. W., Gallaher, P., \& Mouttapa, M. (2004). Using social networks to understand and prevent substance use: A transdisciplinary perspective. Substance Use \& Misuse, 39(10-12), 1685-1712.

Van der Weele, T. J. (2011). Sensitivity analysis for contagion effects in social networks. Sociological Methods \& Research, 40(2), 240-255.

Veenstra, M. Y., Lemmens, P. H., Friesema, I. H., Garretsen, H. F., Knottnerus, J. A. É., \& Zwietering, P. J. (2006). A literature overview of the relationship between life-events and alcohol use in the general population. Alcohol and Alcoholism, 41(4), 455-463.

Wasserman, S., \& Faust, K. (1994). Social network analysis. New York, NY, United States: Cambridge University Press.

Wong, E. C., Palaniappan, L. P., \& Lauderdale, D. S. (2010). Using name lists to infer Asian racial/ethnic subgroups in the healthcare setting. Medical Care, 48(6), 540-546.

Zhou, M. (2009). Contemporary Chinese America: Immigration, ethnicity, and community transformation. Philadelphia, PA, United States: Temple University Press. 